\title{
BMJ Global Health Public health education post-COVID-19: a proposal for critical revisions
}

\author{
Abdul Ghaffar (1) , ${ }^{1}$ Sabina Faiz Rashid, ${ }^{2}$ Rhoda Kitti Wanyenze, ${ }^{3}$ Adnan A Hyder ${ }^{4}$
}

To cite: Ghaffar A, Rashid SF, Wanyenze RK, et al. Public health education postCOVID-19: a proposal for critical revisions. BMJ Global Health 2021;6:e005669. doi:10.1136/ bmjgh-2021-005669

Received 10 March 2021 Accepted 11 March 2021

Check for updates

C) Author(s) (or their employer(s)) 2021. Re-use permitted under CC BY-NC. No commercial re-use. See rights and permissions. Published by BMJ.

${ }^{1}$ Alliance for Health Policy and Systems Research, World Health Organization, Geneva, Switzerland

${ }^{2}$ BRAC University James P Grant School of Public Health, Dhaka, Bangladesh

${ }^{3}$ School of Public Health, Makerere University, Kampala, Uganda

${ }^{4}$ George Washington University Milken Institute of Public Health, Washington, DC, USA

Correspondence to

Dr Abdul Ghaffar:

ghaffara@who.int
Improving the health of people is an essential and perhaps one of the most important functions of any government; health is not only a contributor to overall development but also an important factor in reducing poverty. To achieve health of their populations, nations build health infrastructure and invest in a well-trained health workforce. Public health knowledge, expertise and a skilled workforce play a critical role in prevention of disease, promotion of health, developing programmes, monitoring and evaluation of health systems. Schools of public health (and allied institutions) all over the world play a key role in the production of such a workforce and have traditionally focused on competencies in areas such as epidemiology, statistics, health systems, disease prevention, health economics and environmental health.

COVID-19 is the first pandemic to strike the world since early 1900 s and has magnified the existing inequalities and inequities around the world. Addressing the pandemic requires not only a biomedical approach but also incorporating a broader social sciences approach to health, and most fundamentally, listening and learning from existing diverse communities and health systems, flexibility and capacity to work across sectors, and recognition of social justice, equity and human rights as basic principles, while undertaking public health actions in diverse contexts. This situation has also provoked thinking around potential lessons for public health education. ${ }^{1}$ Just as earlier societal, political and epidemiological shifts prompted developments within public health, we believe that a strengthened public health can emerge from these tumultuous times.

The ongoing pandemic has clearly shown the global health community that there is a need to further strengthen capacity, competencies and knowledge in some areas of public health taught at this point, such as the politics of public health, working with communities in our approach to community engagement and building trust, and promoting interdisciplinary research. However, there are additional areas of knowledge and competencies that are critical to respond and manage such pandemics. The pandemic demands new investments in schools of public health, so that they develop and implement the delivery of some new courses and methods for achieving relevant competencies. We propose at least four more areas for consideration by schools of public health for the development of new or strengthened educational strategies in preparation of a post-COVID world.

First, and perhaps quite essential, is training and expertise in supply chain management. Supply chain management with a focus on prevention and healthcare is often taught in management schools but is either not covered or required in schools of public health. Procurement, storage, and distribution of drugs and other supplies, such as masks and other personal protective devices; equipment like ventilators; and COVID-19 vaccines have become a serious challenge, not only for the ministries of health but also for the global health agencies. This challenge requires expertise and contextualised solutions, in the current global public health workforce and that can change not only the future of COVID-19 and other disease threats but also health programmes in general.

A second need is expertise and proficiency to identify and diminish the effect and spread of misinformation and fake news. The WHO calls this an 'infodemic' ${ }^{23}$-a vast array of information online and offline that undermines public health through disinformation and misinformation. To mitigate the impact of this infodemic, the WHO urges member states to increase their efforts to communicate clearly, taking into consideration the cultural perspectives of responses to epidemics/pandemics, scientifically accurate information and for technology companies-particularly social media businesses-to react more responsibly in relation to health communication and 
education. The infodemic has been linked to growing vaccine hesitancy against the COVID-19 vaccine and public anger and anxieties against preventive measures such as lockdowns. ${ }^{3}{ }^{4}$ While health communication is central to public health education, it has often not kept up with the incredibly fast-paced changes in technology and social media. Moreover, sometimes the assumption that top-down communication from experts will prompt behaviour change persists. ${ }^{5}$ However, the power of online communication is that it is unmediated, peer distributed, spread through storytelling with an emotional pull, and is customisable messaging or memeification. ${ }^{6}$ Coupled with this is the growing disregard and distrust of experts and increasingly violent rhetoric employed against them. ${ }^{7} \mathrm{We}$ fear that such rapid and revolutionary changes may be simply far ahead of what is traditionally taught in many schools of public health. Public health professionals need to understand the importance of this, and learn and use communication messaging and guidelines within the new information ecology, and to be culturally appropriate and contextualised rather than being solely based on clinical management approaches, as was seen in many countries to manage COVID-19. Public health education must develop leaders who can keep pace, and institutions need to develop pedagogical strategies to learn and understand the new science and art of communication in health.

Third, we propose the development of expertise in learning and application of technologies in collection of data, synthesis of available information and dissemination of decisions in a timely manner. Over the recent past, digital technology has been increasingly a focus of teaching and training in most schools of public health; however, the rapidity of change in such approaches often outpaces usual education updates. We believe that recent leaps in machine-readable technology and artificial intelligence will be a game changer in diagnosing, assessing, and managing health systems especially during emergencies and epidemics.

Finally, we believe that a priority setting and resource allocation should become core to any public health curriculum. While lectures on these topics are often found in courses on management, health systems or ethics, they may not be the focus of required courses or covered in depth. The distribution of personal protective equipment, the allocation issues in vaccines, the ethical concerns around criteria, and the need for careful consideration of key technical and moral issues around COVID-19 have unveiled an important need for such skills in health systems. The public health workforce of the future must be able to negotiate these sensitive and vital issues with an informed, pragmatic and ethical approach; and schools of public health can ensure that their graduates are enabled with these knowledge and critical skills.

We urge deans and directors of schools of public health globally to consider all of the above and mentioned topical areas as core to public health education, and encourage their faculty to develop appropriate courses and enhance their own skills in such training. We also join others to request public health statutory and funding bodies, such as the US National Institutes of Health and Medical Research Councils in countries to provide funds to help develop such programmes and advance needed research in these areas. ${ }^{8}$

As it currently stands, public health education is crafting good scientists, practitioners and decision makers; and many of us are products of the current system. But the current systems may need rapid improvement to produce the type of public health professionals who can respond to pandemics or a post-pandemic world. We believe that public health is the broadest bridge between science and society; and to maintain this position, a thoughtful quality improvement of public health education may be required. We welcome debate and further dialogue on this issue of global relevance.

Contributors $A G$ conceptualised the editorial and wrote the first draft, with equal contribution from AAH, SFR and RKW, providing inputs during the writing process. All authors have reviewed the final version. The corresponding author accepts responsibility as guarantor.

Funding The authors have not declared a specific grant for this research from any funding agency in the public, commercial or not-for-profit sectors.

Competing interests None declared.

Patient consent for publication Not required.

Provenance and peer review Not commissioned; internally peer reviewed.

Data availability statement There are no data in this work.

Open access This is an open access article distributed in accordance with the Creative Commons Attribution Non Commercial (CC BY-NC 4.0) license, which permits others to distribute, remix, adapt, build upon this work non-commercially, and license their derivative works on different terms, provided the original work is properly cited, appropriate credit is given, any changes made indicated, and the use is non-commercial. See: http://creativecommons.org/licenses/by-nc/4.0/.

\section{ORCID iD}

Abdul Ghaffar http://orcid.org/0000-0002-8629-4526

\section{REFERENCES}

1 Brownson RC, Burke TA, Colditz GA, et al. Reimagining public health in the aftermath of a pandemic. Am J Public Health 2020;110:1605-10.

2 Claire Wardle: tackling the infodemic. Available: https://www.who.int/ bulletin/volumes/99/3/21-030321.pdf?ua=1 [Accessed 23 Feb 2021].

3 World Health Organization. Joint statement by who, un, UNICEF, UNDP, UNESCO, UNAIDS, ITU, un global pulse and IFRC. managing the COVID-19 infodemic promoting healthy behaviours and mitigating the harm from misinformation and disinformation, 2020. Available: https://www.who.int/news/item/23-09-2020-managing-the-covid-19infodemic-promoting-healthy-behaviours-and-mitigating-the-harmfrom-misinformation-and-disinformation [Accessed 23 Feb 2021].

4 Loomba S, de Figueriedo A, Piatek SJ. Measuring the impact of COVID-19 vaccine misinformation on vaccination intent in the UK and USA. Nat Hum Behav 2021.

5 Mheidly N, Fares J. Leveraging media and health communication strategies to overcome the COVID-19 infodemic. J Public Health Policy 2020;41:410-20.

6 Perera K, Timms H, Heimans J. New power versus old: to beat antivaccination campaigners we need to learn from them-an essay by Kathryn Perera, Henry Timms, and Jeremy Heimans. BMJ 2019;367:16447.

7 Smith A. Facebook: Steve Bannon's call for Anthony Fauci to be beheaded do not break its rules, Zuckerberg says, 2020. Available: https://www.independent.co.uk/life-style/gadgets-and-tech/stevebannon-anthony-fauci-behead-zuckerberg-facebook-b1722335.html [Accessed 23 Feb 2021]. 
